\title{
Warning Effect Evaluation and Control for Vehicle Turn Signal Sound
}

\author{
Yunfeng Xiang, Yansong He, Zhifei Zhang and Zhongming Xu \\ School of Automotive Engineering, Chongqing University, 400030 Chongqing, China. \\ E-mail: hys68@cqu.edu.cn.
}

(Received 26 January 2021; accepted 20 April 2021)

The sound quality of a turn signal sound is directly related to the driving safety and influences comfort during driving. A turn signal sound and interior noise always exist simultaneously while driving. However, none of the studies are performed to observe and control the change of a turn signal sound when the vehicle interior noise was changed. Therefore, this paper develops a method to evaluate and control the warning effect of a turn signal sound masked by vehicle interior noise. First, the turn signal sound and the vehicle interior noise at different speeds are measured and the time-frequency characteristics of the turn signal sound is analyzed. Second, the pairwise comparison method is applied to subjectively evaluate the warning effect of the sounds and the warning effect of the turn signal sound at 6 speeds relative to that at $40 \mathrm{~km} / \mathrm{h}$ was obtained. Third, a new hearing threshold evaluating the warning effect is developed and used as a sound metric. This metric is employed to evaluate objectively the warning effect of warning sounds at different speeds. The subjective evaluation results are consistent with the objective evaluation results, which confirms the validity of objective evaluation. To keep the warning effect of the warning sound during the driving, two methods of controlling the turn signal sound are proposed and will be researched further in the in the future.

\section{INTRODUCTION}

In recent years, vehicle sound quality has been extensively studied, such as vehicle interior noise, ${ }^{1,2}$ engine noise, ${ }^{3,4}$ door closing sound, ${ }^{5,6}$ vehicle suspension shock absorber rattling noise, ${ }^{7}$ horn sound,${ }^{8}$ and warning of electric vehicle. ${ }^{9-11}$ These studies include two major parts: subjective evaluation and objective evaluation. ${ }^{12-14}$ The objective evaluation mainly refers to the use of objective parameters (loudness, sharpness, roughness, fluctuation strength, etc.) to describe the sound quality. Wavelet analysis ${ }^{15}$ and Wigner-Ville distribution ${ }^{7,16}$ were also applied to extract sound characteristics, which were used in the objective evaluation of sound quality. The subjective evaluation mainly includes the grade scoring method, the semantic subdivision method and the pairwise comparison method. ${ }^{17-19}$ After obtaining the subjective and objective evaluation results, the prediction models from objective to subjective were established by methods like the genetic algorithm, ${ }^{20}$ back propagation neural network, ${ }^{21}$ support vector machine, ${ }^{22}$ and deep recurrent neural network ${ }^{23}$ as well.

Although the sound quality of automobiles was extensively investigated, none of the studies have been performed to observe or control the change of the warning effect of turn signal sound when the vehicle interior noise changing. The turn signal consists of the turn light and turn signal sound. The turn light warns other drivers which lane the ego-vehicle will drive in. The function of the turn signal sound is to make the driver of the ego-vehicle aware of the state of the turning through sound signal. The sound of the turn signal can also warn the driver if they forget to turn on or off the turn light. Most vehicles today have a device that removes the indicator when the vehicle completes the turn. The turn signal may be switched off prematurely if the system mistakenly recognized that the vehicle completed the turn, which is very dangerous. The turn signal sound can then warn the driver of the ego-vehicle. If the sound is too low, the state information of the turn signal may be ignored by the driver, which affects the judgment of the driver and might impede driving safety. If the sound is too loud, the hearing comforts of either the driver or the passengers could be seriously affected. Therefore, it is extremely meaningful to evaluate and control the warning effect of the turn signal sound when the vehicle interior noise was changed to improve vehicle sound quality.

When two tones are presented simultaneously, or almost simultaneously, the tone of higher loudness affects the perception of the tone of lower loudness and makes it less noticeable ${ }^{24}$. This is known as the masking effect. Terhardt proposed an algorithm for extracting pitch from complex tonal signals considering the masking effect. ${ }^{25}$ Parizet and Altinsoy researched the detectability of warning sounds for electric vehicles by designing different experiments. ${ }^{9,10}$ Three different background noises were added to four warning sounds and then the subjective evaluation for detectability of twelve warning sounds were conducted in the literature. ${ }^{11}$ Finally, the whine index was developed as sound metrics for an objective evaluation of the detectability combining with the masking effect. The detectability and warning effect are related to the masking effect. Therefore, this paper researched the warning effect of the turn signal sound based on the masking effect.

For the study, it was important to have an objective way to evaluate the warning effect of the warning sound first. Hence, this study deals with the procedure from the subjective evaluation and the objective evaluation to confirm the validity of the objective evaluation. The 15 turn signal sounds used in 


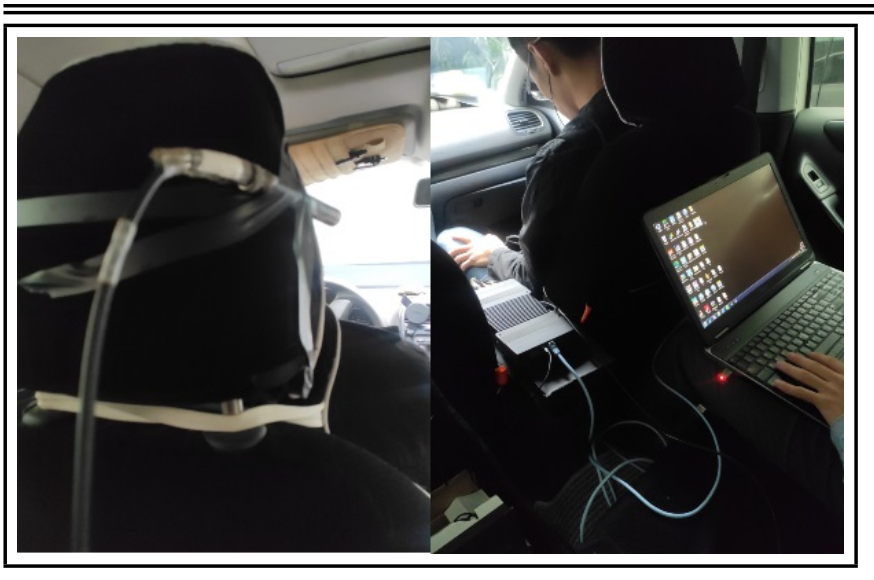

Figure 1. Experimental set-up for sound recording.

the following subjective evaluation experiment and objective evaluation are introduced in section 2 . The subjective evaluation experiment was conducted by using pairwise comparison method and the warning effect of the turn signal sound at different speeds was obtained.in Section 3. The objective evaluation was conducted in section 4 . The new hearing threshold evaluating the warning effect of the turn signal sound was developed and used as a sound metric in Section 4. Then, the validity of the objective evaluation was analyzed and two control methods of the SPL of the turn signal sound were proposed (Section 5). To conclude, the most important aspects were summarized.

\section{MEASUREMENT OF THE TURN SIGNAL SOUND}

\subsection{Measurement Setup}

A passenger car was placed in an open environment (the quiet campus). A microphone (Bruel and Kjaer 4189) was installed near the diver's right ear as shown in Fig. 1. The microphone and LMS SCADAS collector were connected by a BNC cable, and the LMS SCADAS collector and laptop were connected by a network cable. The microphone was calibrated by a sound calibrator (Bruel and Kjaer 4231) before the testing.

\subsection{Procedure of The Noise Recording}

Both the environmental noise and the turn signal sound were recorded respectively on the quiet campus before the engine was ignited. Then, the vehicle was driven into the highway and the speed was controlled by a cruise control system. The vehicle interior noises at the speed of $40 \mathrm{~km} / \mathrm{h}, 50 \mathrm{~km} / \mathrm{h}, 60 \mathrm{~km} / \mathrm{h}$, $70 \mathrm{~km} / \mathrm{h}, 80 \mathrm{~km} / \mathrm{h}, 90 \mathrm{~km} / \mathrm{h}$ and $100 \mathrm{~km} / \mathrm{h}$ were recorded respectively for 30 seconds.

\subsection{Pretreatment}

The measured sound signals were loaded into the LMS Test.lab and were played back. A 6 second sound signal was intercepted from each measured sound signal. Therefore, nine sound samples were obtained as shown in Table 1.
Table 1. Number of nine sound samples.

\begin{tabular}{|c|c|}
\hline No. & sound samples \\
\hline S1 & environmental noise \\
\hline S2 & turn signal sound \\
\hline S3 & vehicle interior noises at $40 \mathrm{~km} / \mathrm{h}$ \\
\hline S4 & vehicle interior noises at $50 \mathrm{~km} / \mathrm{h}$ \\
\hline S5 & vehicle interior noises at $60 \mathrm{~km} / \mathrm{h}$ \\
\hline S6 & vehicle interior noises at $70 \mathrm{~km} / \mathrm{h}$ \\
\hline S7 & vehicle interior noises at $80 \mathrm{~km} / \mathrm{h}$ \\
\hline S8 & vehicle interior noises at $90 \mathrm{~km} / \mathrm{h}$ \\
\hline S9 & vehicle interior noises at $100 \mathrm{~km} / \mathrm{h}$ \\
\hline
\end{tabular}

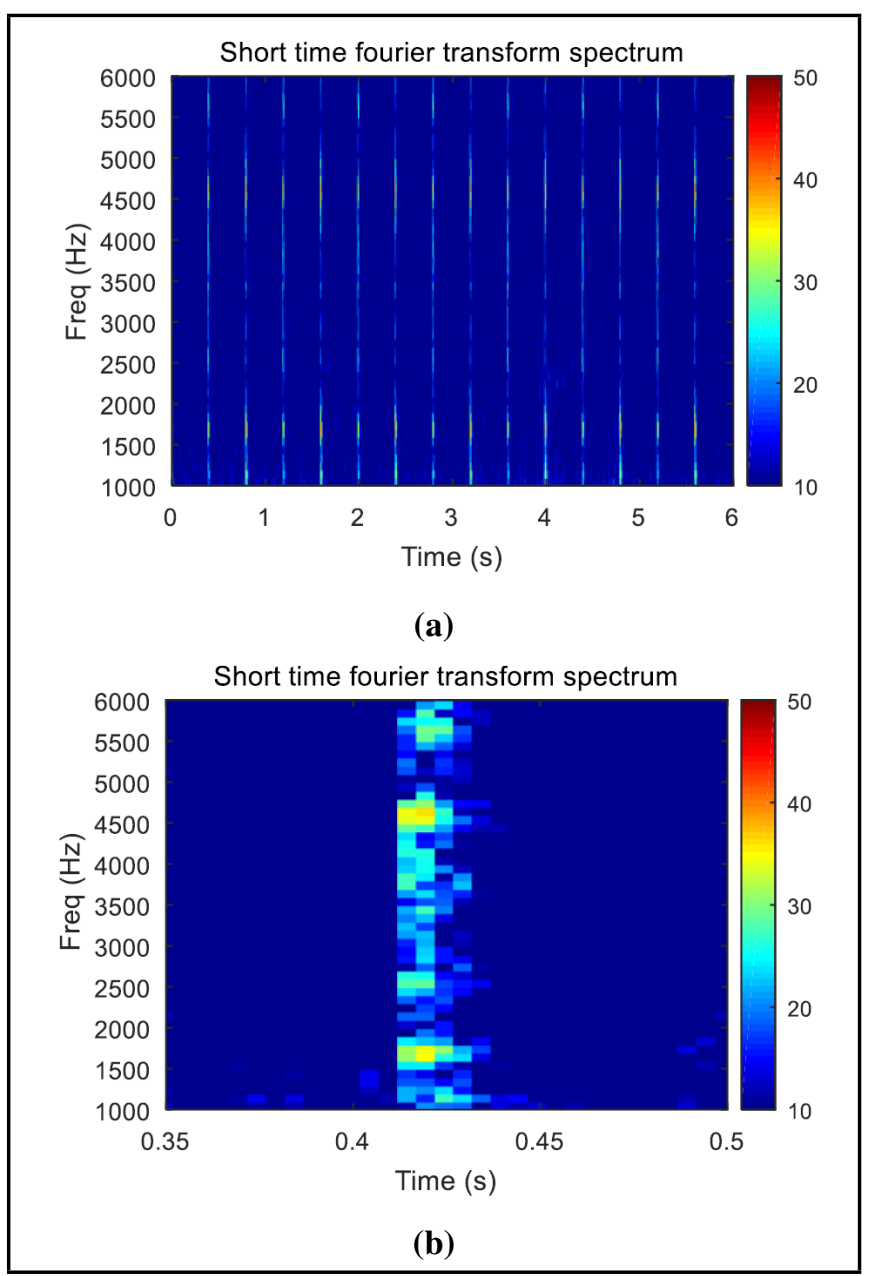

Figure 2. Short time Fourier Transform for the turn signal sound.

\subsubsection{Time-Frequency Analysis of The Turn Signal Sound}

The function of the turn signal sound is to make the driver of the ego-vehicle aware of the state of turning. It was very important to know the time-frequency characteristics of the turn signal sound before the warning effect was discussed. Therefore, the turn signal sound (S2) was analyzed by STFT as shown in Fig. 2a. A partial enlargement of the image from 0.35 seconds to 0.5 seconds is shown in Fig. 2b. Each of audible time width of the turn signal sound was only about $0.02 \mathrm{~s}$ and the main energy of the turn signal sound was concentrated in some discrete frequencies, such as $1600 \mathrm{~Hz}$ and $4500 \mathrm{~Hz}$, as shown in Fig. 2.

The $4500 \mathrm{~Hz}$ frequency slice of STFT of the turn signal sound is shown in Fig. 3. Each cycle contained $2=$ peaks, 


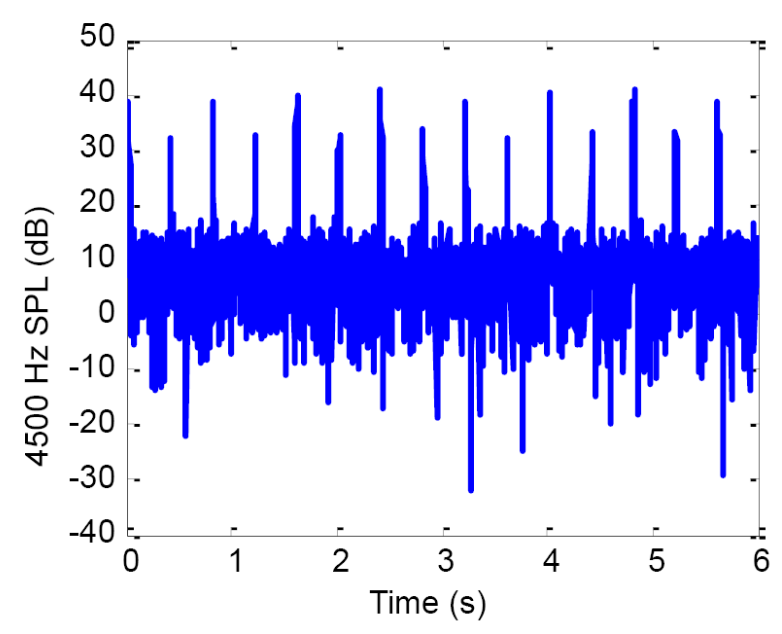

Figure 3. $4500 \mathrm{~Hz}$ frequency slice of STFT.

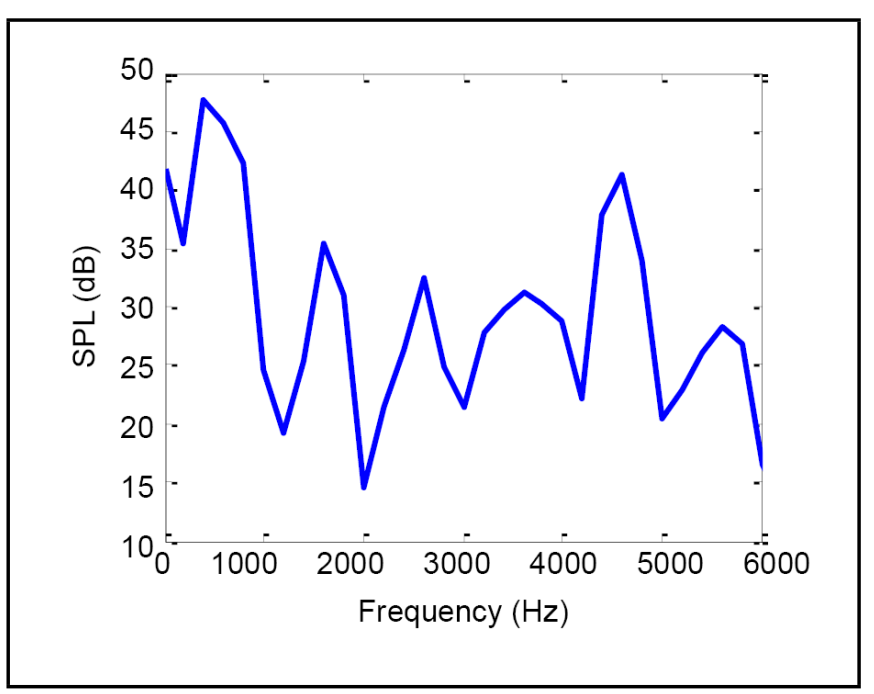

Figure 4. $0.4175 \mathrm{~s}$ time slice of STFT.

which corresponded exactly to the two tones of the turn signal sounds - "tick" tones and "tock" tones. The length of the time for each "tick" and "tock" tone was about 0.02 second according to the partial enlargement of Fig. $2 b$.

The $0.4175 \mathrm{~s}$ time slice of STFT of the turn signal sound is shown in Fig. 4. The peak frequencies of the turn signal sound were at $400 \mathrm{~Hz}, 1600 \mathrm{~Hz}, 2600 \mathrm{~Hz}, 3600 \mathrm{~Hz}, 4600 \mathrm{~Hz}$ and $5600 \mathrm{~Hz}$, as was shown in Fig. 4. However, these peaks may have large deviations due to the low frequency resolution.

To obtain a more accurate peak frequency of the warning sound, the two $0.05 \mathrm{~s}$ adjacent warning tones ("tick" tone and "tock" tone) were respectively intercepted referring to the result of STFT (Fig. 2) and the result of the frequency slice (Fig. 4). The Fourier transform of two adjacent warning tones is shown in Fig. 5. The peak frequencies of the "tick" tone was $420 \mathrm{~Hz}, 1080 \mathrm{~Hz}, 1660 \mathrm{~Hz}, 4560 \mathrm{~Hz}$ and $5880 \mathrm{~Hz}$; and the peak frequencies of the "tock" tone was $420 \mathrm{~Hz}, 1660 \mathrm{~Hz}$, $2520 \mathrm{~Hz}, 4560 \mathrm{~Hz}$ and $5600 \mathrm{~Hz}$. Then the amplitude information of the above peak frequencies as a function of time was extracted. For example, the amplitude information of $4560 \mathrm{~Hz}$ is shown in Fig. 6.

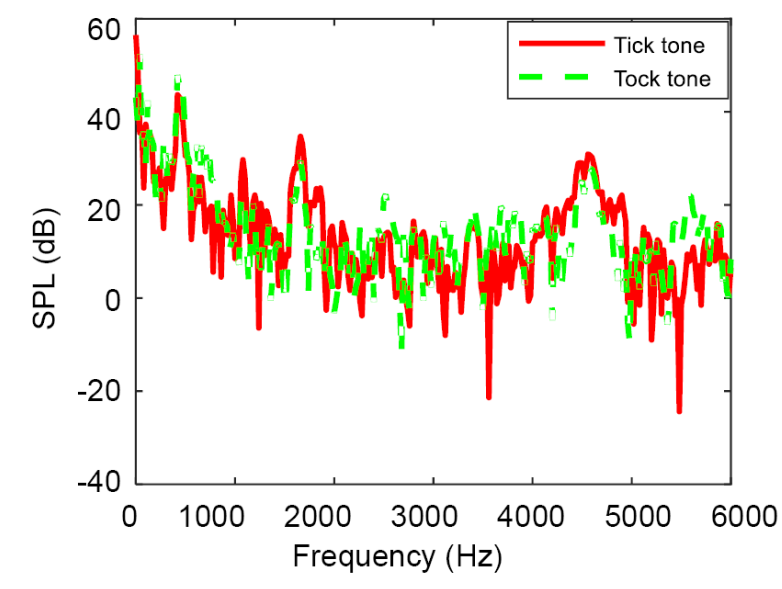

Figure 5. Fourier transform of two adjacent warning tones ("tick" tone and the "tock" tone).

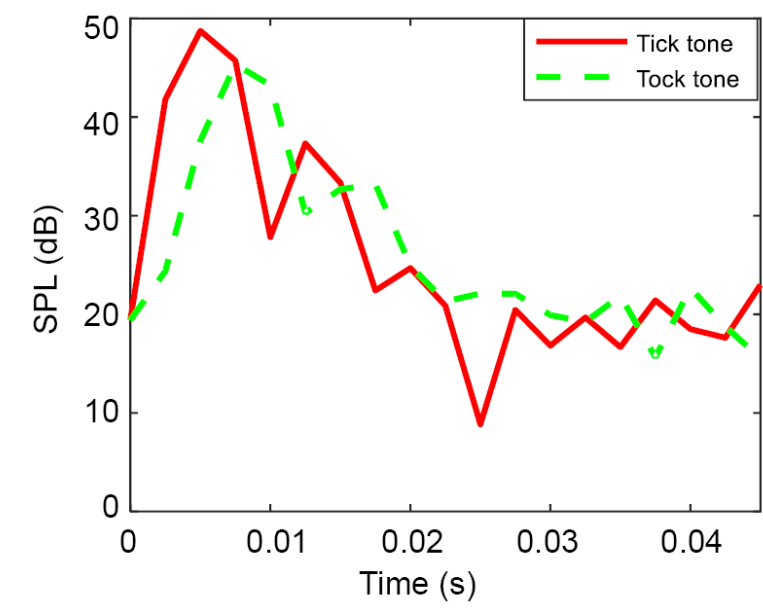

Figure 6. $4560 \mathrm{~Hz}$ amplitude information of two adjacent warning tones ("tick" tone and the "tock" tone).

In conclusion, the turn signal tone was composed of the "tick" tone and the "tock" tone. Each tone was about $0.02 \mathrm{~s}$ and has several peak frequencies.

\subsubsection{Obtaining Sound Samples}

The turn signal sound and the interior noise always exist simultaneously during the driving process. Therefore, to obtain the sound samples of subjective evaluation and objective evaluation, the vehicle interior noises at seven speeds were employed and added to the turn signal sound.

The SPL of the turn signal sound was increased $-9 \mathrm{~dB}$, $7 \mathrm{~dB},-5 \mathrm{~dB},-3 \mathrm{~dB},-1 \mathrm{~dB}, 1 \mathrm{~dB}, 3 \mathrm{~dB}$ and $5 \mathrm{~dB}$ relative to the base sound (S2), respectively, to gain turn signal sounds of different SPLs. For example, that the SPL of S2 was increased $-3 \mathrm{~dB}$ means that the time signal of $\mathrm{S} 2$ changed to 0.717 time of the original turn signal sound. Then the $40 \mathrm{~km} / \mathrm{h}$ vehicle interior noises were employed and added to the seven above different SPLs turn signal sounds. Thus, the eight different SPLs turn signal sounds at $40 \mathrm{~km} / \mathrm{h}$ were obtained. Therefore, the number of turn signal sounds used by this paper was 15 by 


\begin{tabular}{|c|c|c|c|c|c|}
\hline No. & $\begin{array}{c}\text { SPLs } \\
\text { changes } \\
\text { of S2 }\end{array}$ & $\begin{array}{c}\text { vehicle } \\
\text { interior } \\
\text { noise }\end{array}$ & $\begin{array}{c}\text { Loudness } \\
\text { (sone) }\end{array}$ & $\mathrm{dB}(\mathrm{A})$ & $\begin{array}{c}\mathrm{dB}(\mathrm{A}) \\
\text { (turn signal } \\
\text { sound) }\end{array}$ \\
\hline 1 & $0 \mathrm{~dB}$ & $40 \mathrm{~km} / \mathrm{h}$ & 4.05 & 51.92 & 22.41 \\
\hline 2 & $0 \mathrm{~dB}$ & $50 \mathrm{~km} / \mathrm{h}$ & 7.06 & 55.71 & 22.41 \\
\hline 3 & $0 \mathrm{~dB}$ & $60 \mathrm{~km} / \mathrm{h}$ & 7.46 & 56.19 & 22.41 \\
\hline 4 & $0 \mathrm{~dB}$ & $70 \mathrm{~km} / \mathrm{h}$ & 7.76 & 55.64 & 22.41 \\
\hline 5 & $0 \mathrm{~dB}$ & $80 \mathrm{~km} / \mathrm{h}$ & 8.02 & 57.73 & 22.41 \\
\hline 6 & $0 \mathrm{~dB}$ & $90 \mathrm{~km} / \mathrm{h}$ & 9.05 & 60.17 & 22.41 \\
\hline 7 & $0 \mathrm{~dB}$ & $100 \mathrm{~km} / \mathrm{h}$ & 8.59 & 61.47 & 22.41 \\
\hline 8 & $-9 \mathrm{~dB}$ & $40 \mathrm{~km} / \mathrm{h}$ & 4.03 & 51.91 & 13.45 \\
\hline 9 & $-7 \mathrm{~dB}$ & $40 \mathrm{~km} / \mathrm{h}$ & 4.03 & 51.91 & 15.42 \\
\hline 10 & $-5 \mathrm{~dB}$ & $40 \mathrm{~km} / \mathrm{h}$ & 4.03 & 51.92 & 17.44 \\
\hline 11 & $-3 \mathrm{~dB}$ & $40 \mathrm{~km} / \mathrm{h}$ & 4.04 & 51.92 & 19.42 \\
\hline 12 & $-1 \mathrm{~dB}$ & $40 \mathrm{~km} / \mathrm{h}$ & 4.04 & 51.92 & 21.44 \\
\hline 13 & $1 \mathrm{~dB}$ & $40 \mathrm{~km} / \mathrm{h}$ & 4.05 & 51.92 & 23.43 \\
\hline 14 & $3 \mathrm{~dB}$ & $40 \mathrm{~km} / \mathrm{h}$ & 4.07 & 51.92 & 25.44 \\
\hline 15 & $5 \mathrm{~dB}$ & $40 \mathrm{~km} / \mathrm{h}$ & 4.09 & 51.93 & 27.42 \\
\hline
\end{tabular}

combining the seven vehicle interior noises and the different SPLs of the turn signal sound, as shown in Table 2. No. 1 to No. 7 were the combination of the same turn signal sound and the vehicle interior noise at different speeds, while No. 8 to No. 15 were the combination of different SPLs turn signal sound and the vehicle interior noise at $40 \mathrm{~km} / \mathrm{h}$. As shown in Table 2, the value of A-weighted-SPL of the vehicle interior noise increases with the vehicle speeds. Except for the speed of $100 \mathrm{~km} / \mathrm{h}$, the loudness of the vehicle interior noise also rose as the vehicle speed increased. The A weighted SPL of the turn signal sounds was lower than that of the vehicle interior noise.

\section{SUBJECTIVE EVALUATION}

The subjective evaluation for the warning effect (warning strength) of the turn signal sound in vehicle was performed. For this test, 20 persons participated the subjective evaluation. The average age of the trial participants was 24 years old. Their auditory systems were healthy and none of the participants has any known diagnosed hearing problems.

\subsection{Warning Effect}

The 15 turn signal sounds were divided into categories of $\mathrm{A}$ and B as shown in Fig. 7. Category A contained 6 turn signal sounds (from No. 2 to No. 7), which are the synthesis of the same turn signal sound and the vehicle interior noise at different speeds. Category B contained 9 turn signal sounds (from No. 8 to No. 15 and No. 1), which were the synthesis of different SPLs of warning sounds and the vehicle interior noise at $40 \mathrm{~km} / \mathrm{h}$. Then, the warning effect of one sound from category A and each sound from category B was respectively compared by using pairwise comparison ${ }^{17,19,26}$ and the warning effect of the turn signal sound of A relative to B was obtained. Some tests were operated before the experiment design and the test results showed that it was enough to obtain reliable subjective evaluation results that the one sound from category A compared with the seven sounds from category B. Therefore, each sound from category A was only compared with the 7 sounds from category B on the right side of Fig. 7. For example, No. 2

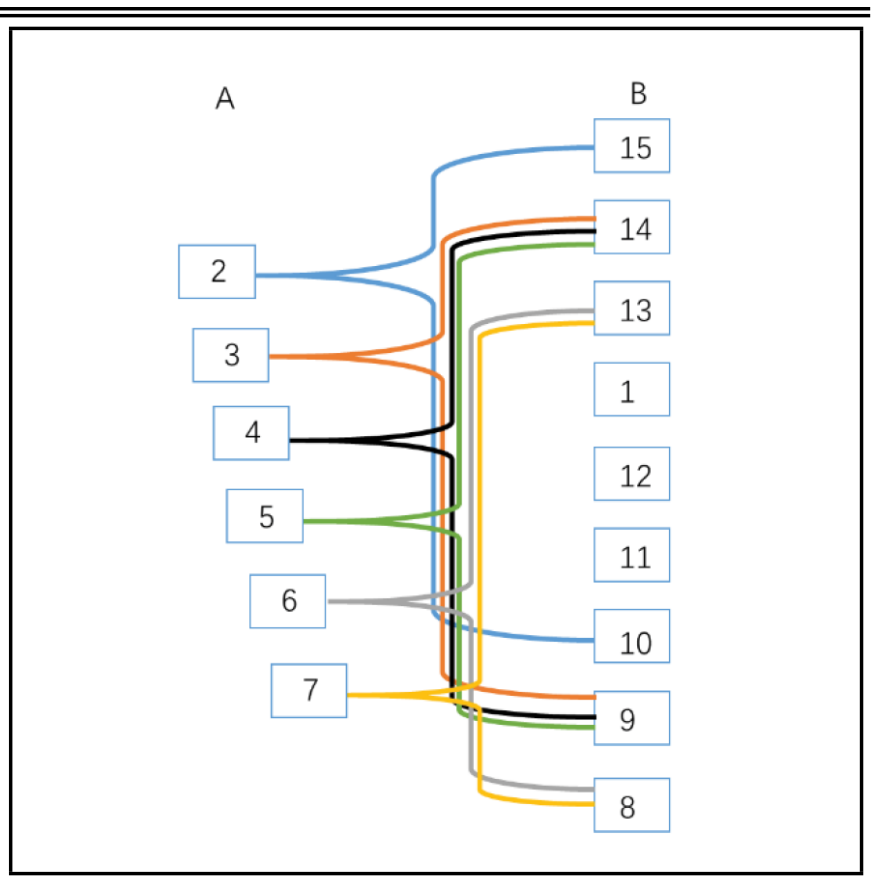

Figure 7. Grouping map of subjective evaluation.

was compared with No. 10 , No. 11 , No. 12 , No. 1 , No. 13 , No. 14 . Then No. 15 . No. 3 , No. 4 , No. 5 , No. 6 , and No. 7 were processed similarly. Therefore, the 42 comparison groups were obtained.

For the listeners, the 42 comparison groups were randomly numbered. Each comparison group included sound I (one from category A) and sound J (one from category B). When comparing, the evaluator listened to sound I first, then listened to sound J. If the warning strength of sound I was bigger $(I>J)$, 1 was selected. And if there was no significant difference between the two $(I=J)$, 0 was selected, otherwise -1 was selected $(I<J)$.

\subsection{Data Processing}

After obtaining the evaluation results of the above 20 evaluators, the normal order (the SPLs of the turn signal were from small to large at $40 \mathrm{~km} / \mathrm{h}$ ) was first returned from the random number. Then the sum of all evaluation results (20 evaluation results) of each comparison group was recorded as S. The final evaluation results of each comparison group were obtained according to the following three criterions.

1. The condition for determining $I>J$ : The number of people who assessed $I>J$ was at least one-third of the total number of people more than the number of people who assessed $I<J$, which was $S \geq 7$. If the condition was satisfied, the final evaluation result was recorded as 1.

2. The condition for determining $I<J$ : The number of people who assessed $I<J$ was at least one-third of the total number of people more than the number of people who assessed $I>J$, which was $S l e-7$. If the condition was satisfied, the final evaluation result was recorded as $-1$.

3. The condition for determining $I=J$ : neither condition 


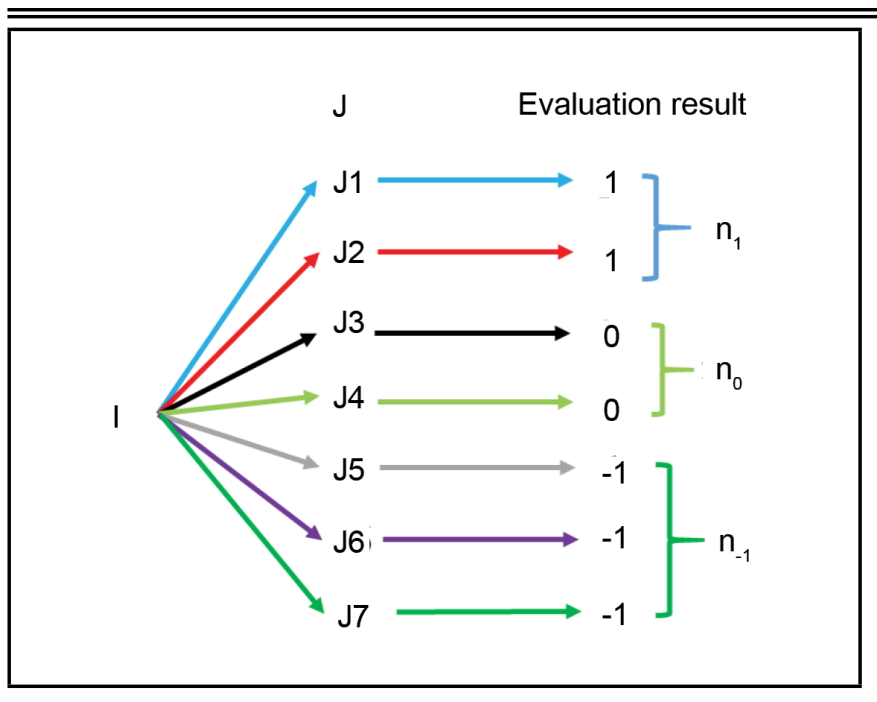

Figure 8. The evaluation results of turn signal sound at the one of speeds.

(1) nor condition (2) was satisfied, which was $-7<S<$ 7. If the condition was satisfied, the final evaluation result was recorded as 0 .

The evaluation result (S) range was between -20 and 20 . There were 14 values from -20 to -7 or from 7 to 20 . There were 13 values from -6 to 6 . Therefore, 7 ( $1 / 3$ of 20 ) was chosen as threshold in above three criterions.

For example, the evaluation results of 20 evaluators for No. 2 and No. 11 are shown in Table 3. All final evaluation results $\mathrm{S}$ of 20 evaluators for No. 2 and No. 11 is 19 because $\mathrm{S}$ was equal to the sum of the evaluation results of 20 evaluators. The warning effect of No. 2 was more obvious than that of No. 11 because of $S \geq 7$. Similarly, the final evaluation results of others comparison groups or the final evaluation results at different speeds can be gained. Such as, the evaluation result of turn signal sound at $50 \mathrm{~km} / \mathrm{h}$ (No. 2 compared with No. 10, No. 11 , No. 12 , No. 1 , No. 13 , No. 14 and No. 15.) is shown in Table 4.

After obtaining the final evaluation results of each comparison group, the number of $1\left(n_{1}\right)$ and the number of $0\left(n_{0}\right)$ at each speed were counted as shown in Fig. 8. Because the comparison results of each speed were ranked from small to large of the warning effect of sound $\mathrm{J}$, the warning effect of sound I was more obvious than that of sound $\mathbf{J}$ from the first comparison group to the $n_{1}$ th comparison group; the warning effect of sound I was same as sound $\mathbf{J}$ from the $\left(n_{1}+1\right)$ th comparison group to the $\left(n_{1}+n_{0}\right)$ th comparison group and the warning effect of sound $\mathbf{J}$ was more obvious than that of sound I from the $\left(n_{1}+n_{0}+1\right)$ th comparison group to the 7 th comparison group. Therefore, the warning effect of I was between that of the $n_{1}$ th sound $\mathbf{J}$ and the $\left(n_{1}+n_{0}+1\right)$ th sound $\mathbf{J}$, and it was considered that the warning effect of sound I was the same as that of the $n_{1}+\frac{n_{0}}{2}+\frac{1}{2}$ sound $\mathbf{J}$.

For example, $n_{1}=2, n_{0}=2$, and $n_{1}+n_{0}+1=5$ for the evaluation result of turn signal sound at $50 \mathrm{~km} / \mathrm{h}$ as shown in Table 4 . The warning effect of the turn signal sound at $50 \mathrm{~km} / \mathrm{h}$ was between that of the $2 \mathrm{nd}$ sound $\mathrm{J}$ and the 5 th sound J. Further, the warning effect was the same as the average of the warning effect of the third and fourth sound J because $n_{1}+\frac{n_{0}}{2}+\frac{1}{2}=3.5$. That was, the warning effect of the turn signal sound at $50 \mathrm{~km} / \mathrm{h}$ was the same as the turn signal sound whose SPL was reduced by $0.5 \mathrm{~dB}$ at $40 \mathrm{~km} / \mathrm{h}$. The warning effect results of the warning sound at the vehicle speed from $50 \mathrm{~km} / \mathrm{h}$ to $100 \mathrm{~km} / \mathrm{h}$ were shown in Table 5 . The warning effects of the turn signal sound at $60 \mathrm{~km} / \mathrm{h}, 70 \mathrm{~km} / \mathrm{h}$ and $80 \mathrm{~km} / \mathrm{h}$ were the same as the turn signal sound whose SPL was reduced by $2 \mathrm{~dB}$ at $40 \mathrm{~km} / \mathrm{h}$, while the effects at $90 \mathrm{~km} / \mathrm{h}$ and $100 \mathrm{~km} / \mathrm{h}$ were the same as that reduced by $3 \mathrm{~dB}$ at $40 \mathrm{~km} / \mathrm{h}$.

\section{OBJECTIVE EVALUATION}

The masking effect of a sound in the background noise is related to the warning effect of the sound in the background noise. Therefore, the warning effect of the warning sound was objectively evaluated combining with theory of masking in this section.

\subsection{Method of Extracting Tonal Components of Vehicle Interior Noise}

When the occurrence time of the vehicle interior noise was the same or close to that of the turn signal sound, the vehicle interior noise would influence the warning effect of the turn signal sound. It is very similar to the masking effect. Therefore, the warning effect of the warning sound masked by the vehicle interior noise was calculated referring to the masking effect. According to reference, ${ }^{25}$ it was necessary to extract the frequency domain information of the vehicle interior noise in each short period before calculating the masking effect of the vehicle interior noise. The following was a method to extract the frequency domain information of the vehicle interior noise.

The vehicle interior noise was analyzed by Short time Fourier Transform. The hanning window of 0.1 second with an overlap rate of 0.5 was selected. After the SPLs of each window were obtained, tonal components were extracted in the following way.

$$
\begin{gathered}
L_{i-1}<L_{i}>L_{i+1} . \\
L_{i}-L_{i-j}>7 ; \quad j=-3,-2,2,3 .
\end{gathered}
$$

Here $L_{i}$ was the relative SPL of the $i$ th spectrum samples (fi), $L_{i-1}$ was the next lower, and $L_{i+1}$ was the next higher sample. If the above two conditions were fulfilled, it was assumed that the considered group of seven spectral samples represented a tonal component of the vehicle interior noise. ${ }^{25}$

After the frequency $f_{i}$ and the SPL $L_{i}$ of the tonal component were obtained, the good approximation to the precise component frequency $f_{c}$ and the SPL $L_{c}$ were corrected by the below formula.

$$
\begin{gathered}
f c=f i+0.46(\mathrm{~Hz} / \mathrm{dB})(L i+1-L i-1) . \\
L_{c}=L_{i}+2 .
\end{gathered}
$$

Therefore, the number $\mathrm{N}$ of tonal components, the frequency $f_{c}$, and the SPL $L_{c}$ of every component were obtained by the above calculation. 
Table 3. Comparison results for No.2 and No.11.

\begin{tabular}{|c|c|c|c|c|c|c|c|c|c|c|c||}
\hline Evaluator & P1 & P2 & P3 & P4 & P5 & P6 & P7 & P8 & P9 & P10 & P11 \\
\hline Result & 1 & 1 & 1 & 1 & 1 & 1 & 1 & 1 & 1 & 1 & 1 \\
\hline Evaluator & P12 & P13 & P14 & P15 & P16 & P17 & P18 & P19 & P20 & & \\
\hline Result & 1 & 0 & 1 & 1 & 1 & 1 & 1 & 1 & 1 & & \\
\hline
\end{tabular}

Table 4. Evaluation results of the turn signal sound at $50 \mathrm{~km} / \mathrm{h}$.

\begin{tabular}{|c|c|c|c|c|}
\hline \multicolumn{2}{|r|}{ I } & \multicolumn{2}{|r|}{$\mathrm{J}$} & \multirow[b]{2}{*}{ result } \\
\hline $\begin{array}{c}\text { changing } \\
\text { of S2 }\end{array}$ & $\begin{array}{c}\text { vehicle } \\
\text { interior noise }\end{array}$ & $\begin{array}{c}\text { changing } \\
\text { of S2 }\end{array}$ & $\begin{array}{c}\text { vehicle } \\
\text { interior noise }\end{array}$ & \\
\hline $0 \mathrm{~dB}$ & $50 \mathrm{~km} / \mathrm{h}$ & $-5 \mathrm{~dB}$ & $40 \mathrm{~km} / \mathrm{h}$ & 1 \\
\hline $0 \mathrm{~dB}$ & $50 \mathrm{~km} / \mathrm{h}$ & $-3 \mathrm{~dB}$ & $40 \mathrm{~km} / \mathrm{h}$ & 1 \\
\hline $0 \mathrm{~dB}$ & $50 \mathrm{~km} / \mathrm{h}$ & $-1 \mathrm{~dB}$ & $40 \mathrm{~km} / \mathrm{h}$ & 0 \\
\hline $0 \mathrm{~dB}$ & $50 \mathrm{~km} / \mathrm{h}$ & $0 \mathrm{~dB}$ & $40 \mathrm{~km} / \mathrm{h}$ & 0 \\
\hline $0 \mathrm{~dB}$ & $50 \mathrm{~km} / \mathrm{h}$ & $1 \mathrm{~dB}$ & $40 \mathrm{~km} / \mathrm{h}$ & -1 \\
\hline $0 \mathrm{~dB}$ & $50 \mathrm{~km} / \mathrm{h}$ & $3 \mathrm{~dB}$ & $40 \mathrm{~km} / \mathrm{h}$ & -1 \\
\hline $0 \mathrm{~dB}$ & $50 \mathrm{~km} / \mathrm{h}$ & $5 \mathrm{~dB}$ & $40 \mathrm{~km} / \mathrm{h}$ & -1 \\
\hline
\end{tabular}

Table 5. Warning effect (relative to $40 \mathrm{~km} / \mathrm{h}$ ) of warning sound at different speeds.

\begin{tabular}{|c|c|c|c|c|c|c|}
\hline Speed $(\mathrm{km} / \mathrm{h})$ & 50 & 60 & 70 & 80 & 90 & 100 \\
\hline SPL changes at $40 \mathrm{~km} / \mathrm{h}(\mathrm{dB})$ & -0.5 & -2 & -2 & -2 & -3 & -3 \\
\hline
\end{tabular}

\subsection{Masking Effect of The Warning Noise Masked by The Vehicle Interior Noise}

The tonal components masked by background noise and other tonal component were extracted using the equation given by Terhardt. ${ }^{25}$

$$
\begin{gathered}
L X\left(f_{\mu}\right)=L\left(f_{\mu}\right)-10 \log \left[\left(\sum_{\substack{\nu \\
v \neq \mu}}^{N} 10^{L_{E \nu}\left(f_{\mu}\right) /(20 \mathrm{~dB})}\right)^{2}+\right. \\
\left.I_{N \mu}+10^{L_{T H}\left(f_{u}\right) /(10 \mathrm{~dB})}\right] \mathrm{dB} .
\end{gathered}
$$

Here $L\left(f_{\mu}\right)$ was the SPL of the $\mu$ th tonal component. $L_{E \nu}\left(f_{\mu}\right)$ was the excitation level which was produced at the peak frequency $f_{\mu}$ of the turn signal sound by the $\nu$ th tonal component of the vehicle interior noise. $I_{N \mu}$, the noise intensity presented in the critical band of the vehicle interior noise around the considered tonal component, was used to consider the additional masking effect of "noisy" spectral samples, i.e., such samples which cannot be assigned to any tonal component. $L_{T H}\left(f_{\mu}\right)$ was the hearing threshold at the peak frequency $f_{\mu}$ of the turn signal sound.

Because the audible time of the turn signal sound was very short, and the SPL was relatively small compared to the vehicle interior noise, the masking effect of the warning sound was not considered. Only the warning effect of the turn signal sound was considered, so it was necessary to calculate the amount of masking effect at the peak frequency of the turn signal sound. The masking effect of turn signal sound masked by the interior noise was equal to the hearing threshold of the turn signal sound that was increased in the vehicle interior noise. Therefore, the new hearing threshold of the turn signal sound in the vehicle interior noise represented the masking effect of the turn signal sound masked by the vehicle interior noise.
The amount of the masking effect of the warning noise that was masked by the vehicle interior noise, or the new hearing threshold $L_{T H 1}\left(f_{\mu}\right)$ of the turn signal sound in the vehicle interior noise was calculated as the following equation..$^{25}$

$$
\begin{aligned}
L_{T H 1}\left(f_{\mu}\right)= & 10 \log \left[\left(\sum_{\nu=1 v \neq \mu}^{N} 10^{L_{E \nu}}\left(f_{\mu}\right) /(20 \mathrm{~dB})\right)^{2}\right. \\
& \left.+I_{N \mu}+10^{L_{T H}\left(f_{u}\right) /(10 \mathrm{~dB})}\right] \mathrm{dB} .
\end{aligned}
$$

The excitation level $L_{E \nu}\left(f_{\mu}\right)$ was specified by

$$
L_{E \nu}\left(f_{\mu}\right)=L_{\nu}-s\left(z_{\nu}-z_{\mu}\right) .
$$

Here $L_{\nu}$ was the SPL of the $\nu$ th tonal component of the vehicle interior noise. Figure $\mathrm{z}$ represents the critical-band rate; thus $z_{\nu}$ and $z_{\mu}$ were the critical-band rates of the $\mu$ th peak frequency $f_{\mu}$ of the turn signal sound and the $\nu$ th components of the vehicle interior noise, respectively. The relationship between frequency and critical-band rate was with high accuracy provided by

$$
z=\left\{13 \arctan [0.76(\mathrm{f} / \mathrm{kHz})]+3.5 \arctan (f / 7.5 \mathrm{kHz})^{2}\right\} \text { Bark. }
$$

Equation (7) represented the triangular shape of the excitation level critical-band rate pattern, where $s$ depicted the steepness of the slopes.

$$
\begin{aligned}
& s=27 \mathrm{~dB} / \text { Bark } \quad \text { if } \quad f_{\mu}<f_{\nu}, \\
& s=\left[-24-\left(0.23 \mathrm{kHz} / \mathrm{f}_{\nu}\right)+\left(0.2 L_{\nu} / \mathrm{dB}\right)\right] \mathrm{dB} / \text { Bark } \\
& \text { if } \quad f \mu>f_{\nu} .
\end{aligned}
$$

The noise intensity $I_{N \mu}$ was obtained by adding the sound intensities of those spectrum samples which corresponded to the particular critical-band rate interval extending from $\left(z_{\mu}-\right.$ 0.5 Bark $)$ to $\left(z_{\mu}+0.5\right.$ Bark $)$, skipping the five central samples $(i-2, i-1, i, i+1, i+2)$ of every component which eventually had been detected in that critical band. It was found that the portion of sound energy which cannot be considered as tonal was considered in this algorithm adequately.

The threshold of hearing, which in Eq. (6) was represented by $L_{T H}\left(f_{\mu}\right)$, was adequately specified by the formula. ${ }^{25}$

$$
\begin{aligned}
& L_{T H}\left(f_{\mu}\right)=\left\{3.64\left(f_{\mu} / \mathrm{kHz}\right)^{-0.8}-\right. \\
& \left.6.5 \exp \left[-0.6\left(f_{\mu} / \mathrm{kHz}-3.3\right)^{2}\right]+10^{-3}\left(f_{\mu} / \mathrm{kHz}\right)^{4}\right\} \mathrm{dB} .
\end{aligned}
$$

According to the above Eqs. (1) to (10), the new hearing thresholds of the peak frequency of the turn signal sound in each short-time Fourier window of the vehicle interior noise were obtained. To show more intuitively the new hearing threshold, the time average of the new hearing thresholds in 


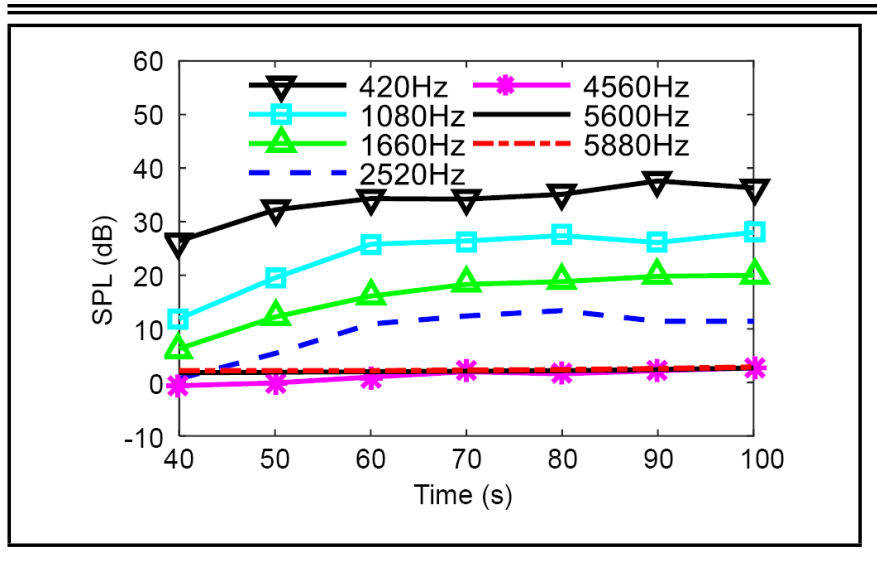

Figure 9. New hearing threshold of the interior noise at different frequencies and at different speeds.

Table 6. New hearing threshold of the interior noise at different frequencies and at different speeds.

\begin{tabular}{||c|c|c|c|c|c|c|c||}
\hline Speed $(\mathrm{km} / \mathrm{h})$ & 40 & 50 & 60 & 70 & 80 & 90 & 100 \\
\hline $420 \mathrm{~Hz}(\mathrm{~dB})$ & 26.4 & 32.2 & 34.3 & 34.2 & 35.1 & 37.6 & 36.3 \\
\hline $1080 \mathrm{~Hz}(\mathrm{~dB})$ & 11.9 & 19.5 & 25.8 & 26.4 & 27.4 & 26.1 & 28.0 \\
\hline $1660 \mathrm{~Hz}(\mathrm{~dB})$ & 6.3 & 12.2 & 16.1 & 18.3 & 18.8 & 19.8 & 20.0 \\
\hline $2520 \mathrm{~Hz}(\mathrm{~dB})$ & 0.7 & 5.4 & 10.9 & 12.4 & 13.4 & 11.4 & 11.4 \\
\hline $4560 \mathrm{~Hz}(\mathrm{~dB})$ & -0.6 & -0.1 & 1.0 & 2.0 & 1.6 & 2.2 & 2.7 \\
\hline $5600 \mathrm{~Hz}(\mathrm{~dB})$ & 1.8 & 1.9 & 2.0 & 2.1 & 2.2 & 2.4 & 2.7 \\
\hline $5880 \mathrm{~Hz}(\mathrm{~dB})$ & 2.2 & 2.2 & 2.2 & 2.3 & 2.4 & 2.6 & 2.9 \\
\hline
\end{tabular}

all windows (6 seconds) was taken as the final new hearing threshold. The results of the new hearing thresholds of the different peak frequencies of the turn signal sound at the different speeds (different vehicle noises) were shown in Table 6 and in Fig. 9. The new hearing threshold proposed in Table 6 is changed according to a vehicle. The new hearing threshold at $420 \mathrm{~Hz}, 1080 \mathrm{~Hz}, 1660 \mathrm{~Hz}$, and $2520 \mathrm{~Hz}$ were relatively large, and with the frequency increasing, the new hearing threshold decreased. The new hearing threshold at $4560 \mathrm{~Hz}, 5600 \mathrm{~Hz}$, and $5880 \mathrm{~Hz}$ was relatively small.

The amplitudes at the peak frequencies of the "tick" and the "tock" sounds minus the new hearing threshold at $50 \mathrm{~km} / \mathrm{h}$ (similar to other vehicle speeds) were shown in Fig. 10. The maximum amplitude at $4560 \mathrm{~Hz}$ was the largest and was greater than $17 \mathrm{~dB}$, and the maximum amplitude at other peak frequencies was less than $17 \mathrm{~dB}$ (less than $17 \mathrm{~dB}$ sound pure tone was not easy to attract attention ${ }^{11}$ ). That was, the warning effect of the $4560 \mathrm{~Hz}$ component of the warning sound almost represented the warning effect of the entire turn signal sound. Therefore, it was only necessary to calculate the new hearing threshold of the $4560 \mathrm{~Hz}$ component of the turn signal sound at the different speeds.

\section{COMPARISON AND CONTROL}

\subsection{Comparison Between Subjective Evaluation and Objective Evaluation}

The warning effect of the turn signal sound at 6 speeds relative to that at $40 \mathrm{~km} / \mathrm{h}$ was obtained by subjective evaluation in section 3 and was expressed as the SPL changes. To facilitate the comparison, the relative new hearing threshold of the turn signal sound at different vehicle speeds was obtained by

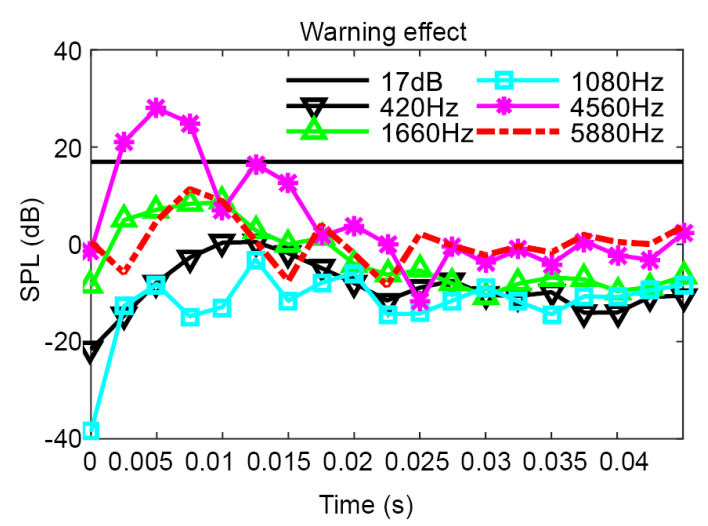

(a)

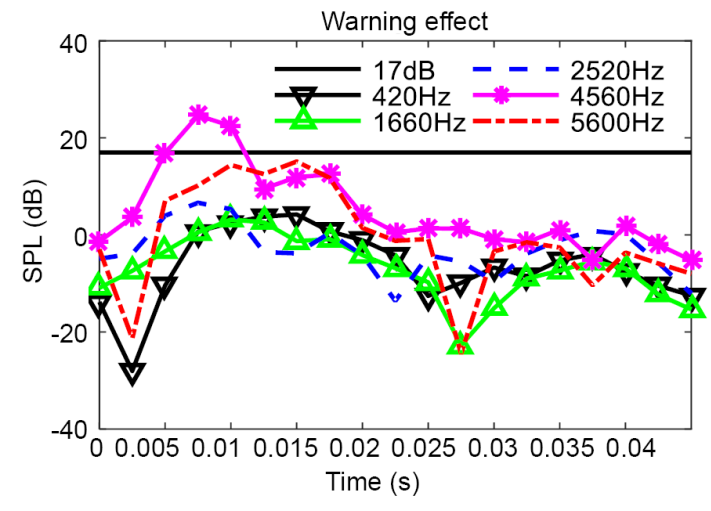

(b)

Figure 10. Different frequencies amplitude information of turn signal sounds at $50 \mathrm{~km} / \mathrm{h}$ : (a) the "tick" tone; (b) the "tock" tone.

Table 7. Comparison table between subjective evaluation and objective evaluation.

\begin{tabular}{||c|c|c|c|c|c|c||}
\hline speed $(\mathrm{km} / \mathrm{h})$ & 50 & 60 & 70 & 80 & 90 & 100 \\
\hline SPL changes $(\mathrm{dB})$ & -0.5 & -2 & -2 & -2 & -3 & -3 \\
\hline $\begin{array}{c}\text { Relative new } \\
\text { hearing threshold }(\mathrm{dB})\end{array}$ & 0.63 & 1.61 & 2.14 & 2.26 & 2.76 & 3.27 \\
\hline
\end{tabular}

subtracting the new hearing threshold at $40 \mathrm{~km} / \mathrm{h}$. The results of subjective evaluation and objective evaluation of the warning effect of the turn signal sound at the 6 speeds are shown in Table 7. The relative SPL of subjective evaluation was inversely proportional to the relative new hearing threshold of objective evaluation. The subjective evaluation can only obtain discrete results, and the calculated new hearing threshold can be continuous. The ratio of the calculated relative new hearing threshold (rounding) to the subjective evaluation result was about -1 , which proved that the opposite number of the relative new hearing threshold represented the warning effect of the warning sound.

\subsection{SPL Control of Turn signal sound}

It has been proved that the opposite number of the relative new hearing threshold of the turn signal sound in the interior noise can be used to indicate the warning effect of the turn signal sound. To keep the warning effect of the turn signal sound during driving, the SPL of turn signal sound can be controlled 


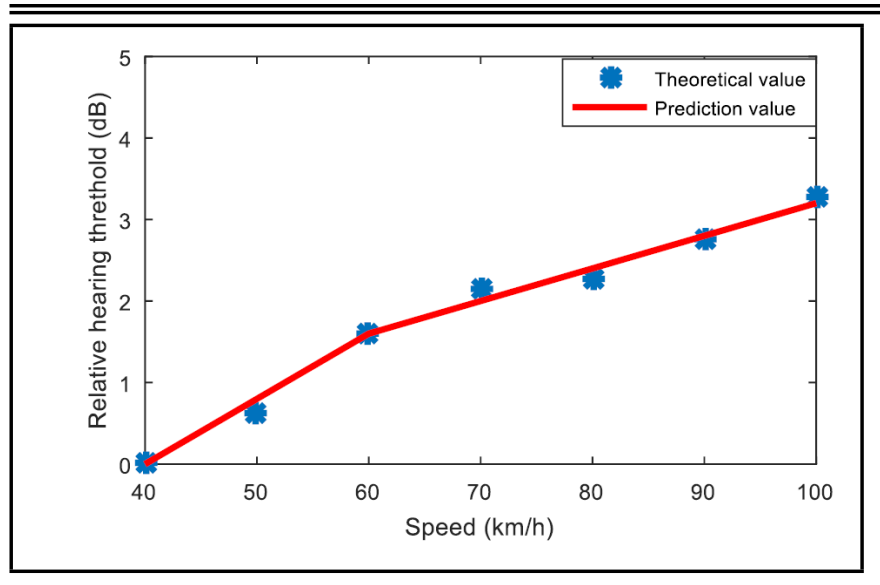

Figure 11. New hearing threshold of the turn signal sound at the different speeds.

according to the relative new hearing threshold as shown in Table 7 and Fig. 11.

The red line was the prediction function, and the equation was as follows:

$$
\begin{aligned}
& L_{R T H 1} v=0.08(v-40) \text { if } 40 \mathrm{~km} / \mathrm{h}<v<60 \mathrm{~km} / \mathrm{h} . \\
& L_{R T H 1} v=0.04 v-0.8 \text { if } 60 \mathrm{~km} / \mathrm{h} \leq v<100 \mathrm{~km} / \mathrm{h} .
\end{aligned}
$$

Here, $v$ was the speed, and $L_{R T H 1}(v)$ was the relative new hearing threshold of turn signal sound at the speed $v$. The relative new hearing threshold proposed in is changed according to a vehicle.

To keep the warning effect of the warning sound during the driving, two control methods were considered. Method (1), when the turn signal sound ECU (Electronic Control Unit) obtained the speed, the SPL of the turn signal sound was changed by the turn signal sound speaker according to Eqs. eqrefeq11 and (12). Method (2), a microphone for collecting a noise signal was installed in the vehicle, and the turn signal sound ECU calculated the new hearing threshold (as in section 5), and thereby the buzzer changed the SPL of the turn signal sound according to the new hearing threshold. Due to the influence of environmental noise and varying working conditions, when the requirement was not high, method (1) can roughly control the warning effect of the turn signal sound. To accurately control the warning effect of the turn signal sound, then method (2) recommended. The two control methods will be further researched in the future.

\section{CONCLUSION}

An objective method was developed for evaluating the sound quality of the turn signal sound to control the warning effect of the turn signal sound. To develop this method, a turn signal sound, and the vehicle interior noises at the 7 speeds are tested. Then the turn signal sound was added to the seven vehicle interior noises and eight different SPLs of the turn signal sounds were added to the vehicle interior noise at $40 \mathrm{~km} / \mathrm{h}$, respectively. Therefore, the fifteen turn signal sounds, including the vehicle interior noise, are used for this project.

The subjective evaluation for warning effect of six turn signal sounds at the different speeds relative to that at $40 \mathrm{~km} / \mathrm{h}$ are conducted through pairwise comparison method. The new hearing thresholds of the turn signal sound masked by the different vehicle interior noises at the different peak frequencies are calculated considering the masking effect. The relative new hearing thresholds were consistent with the subjective evaluation results, which proved that the new hearing threshold can be used to represent the warning effect of the turn signal sound in the different vehicle interior noises.

To keep the warning effect of the turn signal sound during driving, two control methods are considered. The two control methods will be tested and verified in the future research. On the other hand, this study is aimed at young healthy people in subjective evaluation and the number of trial participants was limited. The research will be aimed at more people in the future.

\section{AKNOWLEDGEMENT}

The research work of authors is supported by National Natural Science Foundation of China [grant numbers 51275540]. This support is gratefully acknowledged.

\section{REFERENCES}

1 Xu, Z., Xia, X., Lai, S., He, Z. Improvement of interior sound quality for passenger car based on optimization of sound pressure distribution in low frequency. Applied Acoustics., 130(jan.), 43-51, (2018). https://dx.doi.org/10.1016/j.apacoust.2017.08.019

2 Lee, S.K. Objective evaluation of interior sound quality in passenger cars during acceleration. Journal of Sound and Vibration., 310(1-2), 149-168, (2008). https://dx.doi.org/10.1016/j.jsv.2007.07.073

3 Yang Z , Feng H, Ma B , et al. Evaluation and Improvement of the Sound Quality of a Diesel Engine Based on Tests and Simulations[J]. Energies.,13, 1-21, (2020). https://dx.doi.org/10.3390/en13040777

4 Park J H , Park H , Kang Y J . A study on sound quality of vehicle engine sportiness using factor analysis[J]. Journal of Mechanical Science and Technology, 34(9), 1-11, (2020). https://dx.doi.org/10.1007/s12206-020-0805-0

5 Yaln E , Bilal H, Yagc A, et al. A Numerical Approach for Sound Quality of Vehicle Doors[J]. Acoustics Research Letters Online., ,25(1), 1-6, (2020). https://dx.doi.org/10.20855/ijav.2020.25.11475

6 Bezat, M.-C., Kronland-Martinet, R., Roussarie, V., Ystad, S.L. From acoustic descriptors to evoked quality of car door sounds. Journal of the Acoustical Society of America., 136(1), 226-241, (2014). https://dx.doi.org/10.1121/1.4883364

7 Huang, H.B., Li, R.X., Huang, X.R., Yang, M.L., Ding, W.P. Sound quality evaluation of vehicle suspension shock 
absorber rattling noise based on the Wigner-Ville distribution. Applied Acoustics., 100(DEC.15), 18-25, (2015). https://dx.doi.org/10.1016/j.apacoust.2015.06.018

${ }^{8}$ Kang, H.-S., Shin, T., Lee, S.-K., Park, D.C. Design optimization of a dual-shell car horn for improved sound quality based on numerical and experimental methods. Applied Acoustics., 90, 160-170, (2015). https://dx.doi.org/10.1016/j.apacoust.2014.11.008

${ }^{9}$ Parizet E, Robart R. Detectability and annoyance of warning sounds for electric vehicles[J]. The Journal of the Acoustical Society of America., 133(5), 1-6, (2013). https://dx.doi.org/10.1121/1.4800182

${ }^{10}$ Altinsoy E. The detectability of conventional, hybrid and electric vehicle sounds by sighted, visually impaired and blind pedestrians[C]. INTER-NOISE and NOISE-CON Congress and Conference Proceedings., Innsbruck, (2013).

11 Lee, S.K., Lee, S.M., Shin. Objective evaluation of the sound quality of the warning sound of electric vehicles with a consideration of the masking effect: Annoyance and detectability. International Journal of Automotive Technology., 18(4), 699-705, (2017). https://dx.doi.org/10.1007/s12239-017-0069-6

12 Rey Gozalo, G., Trujillo Carmona, J., Barrigon Morillas, J.M., Vilchez-Gomez, R., Gomez Escobar, V. Relationship between objective acoustic indices and subjective assessments for the quality of soundscapes. Applied Acoustics., 97(oct.), 1-10 (2015). https://dx.doi.org/10.1016/j.apacoust.2015.03.020

${ }^{13}$ M, Pierrette, E, et al. Noise effect on comfort in open-space offices: development of an assessment questionnaire[J]. Ergonomics., 58(1), 96-106, (2015). https://dx.doi.org/10.1080/00140139.2014.961972

${ }^{14}$ Krumbholza, Katrin, Patterson, et al. Microsecond temporal resolution in monaural hearing without spectral cues?[J]. Journal of the Acoustical Society of America., 113(5), 2790-2800, (2003). https://dx.doi.org/10.1121/1.1547438

15 Wang, Y.S. Sound quality estimation for nonstationary vehicle noises based on discrete wavelet transform. Journal of Sound and Vibration., 324(3-5), 1124-1140, (2009). https://dx.doi.org/10.1016/j.jsv.2009.02.034

16 Yang, C. Research on the Sound Metric of Door Slamming Sound Based on Pseudo WIGNER-VILLE Distribution. Journal of Mechanical Engineering., 47(24), 91, (2011). https://dx.doi.org/10.3901/JME.2011.24.091
17 Otto, N., Amman, S., Eaton, C., Lake, S. Guidelines for jury evaluations of automotive sounds. Sound and Vibration., 35(4), 24-47, (2001). https://dx.doi.org/10.4271/1999-01-1822

18 Guo-qing, Di, and, et al. Adjustment on subjective annoyance of low frequency noise by adding additional sound[J]. Journal of Sound \& Vibration., 330, 5707-5715, (2011). https://dx.doi.org/10.1016/j.jsv.2011.06.014

19 Parizet E . Paired Comparison Listening Tests and Circular Error Rates[J]. Acta Acustica United with Acustica., 88(88), 594-598, 2002. https://dx.doi.org/10.1134/1.1494032

${ }^{20} \mathrm{Ke}$, J., Ogura, M., Wang, S.Y. Optimization Models of Sound Systems Using Genetic Algorithms. Computational Lingus., 29(1), 1-18, (2006). https://dx.doi.org/10.1162/089120103321337412

${ }^{21}$ Zhang, E., Hou, L., Shen, C., Shi, Y., Zhang, Y. Sound quality prediction of vehicle interior noise and mathematical modeling using a back propagation neural network (BPNN) based on particle swarm optimization (PSO). Measurement Science and Technology., 27(1), 1-9, (2016). https://dx.doi.org/10.1088/0957-0233/27/1/015801

22 Wu, Z.L., Li, C.H., Ng, J., Leung, K. Location Estimation via Support Vector Regression. IEEE Transactions on Mobile Computing., 6, 311-321, (2007). https://dx.doi.org/10.1109/TMC.2007.42

${ }^{23}$ Keshavarzi, M., Goehring, T., Zakis, J., Turner, R.E., Moore, B.C.J. Use of a Deep Recurrent Neural Network to Reduce Wind Noise: Effects on Judged Speech Intelligibility and Sound Quality. Trends in Hearing., 22, 1-12, (2018). https://dx.doi.org/10.1177/2331216518770964

24 ZWICKER, E. and FASTL, H. Psychoacoustics. Facts and Models. 3rd edn. Springer-Verlag. Berlin, Germany, 71-85, (1999).

25 Terhardt, Ernst. Algorithm for extraction of pitch and pitch salience from complex tonal signals. The Journal of the Acoustical Society of America., 71(3), 679-688, (1982). https://dx.doi.org/10.1121/1.387544

${ }^{26}$ Corrente, S. Figueira, J.R. and Greco, S. Pairwise Comparison Tables within the Deck of Cards Method in Multiple Criteria Decision Aiding., European Journal of Operational Research., 291(2),738-756,(2021). https://dx.doi.org/10.1016/j.ejor.2020.09.036 